\title{
Las ecotecnias como factor de sustentabilidad El caso de las biopiscinas municipales en la ciudad de Guadalajara
}

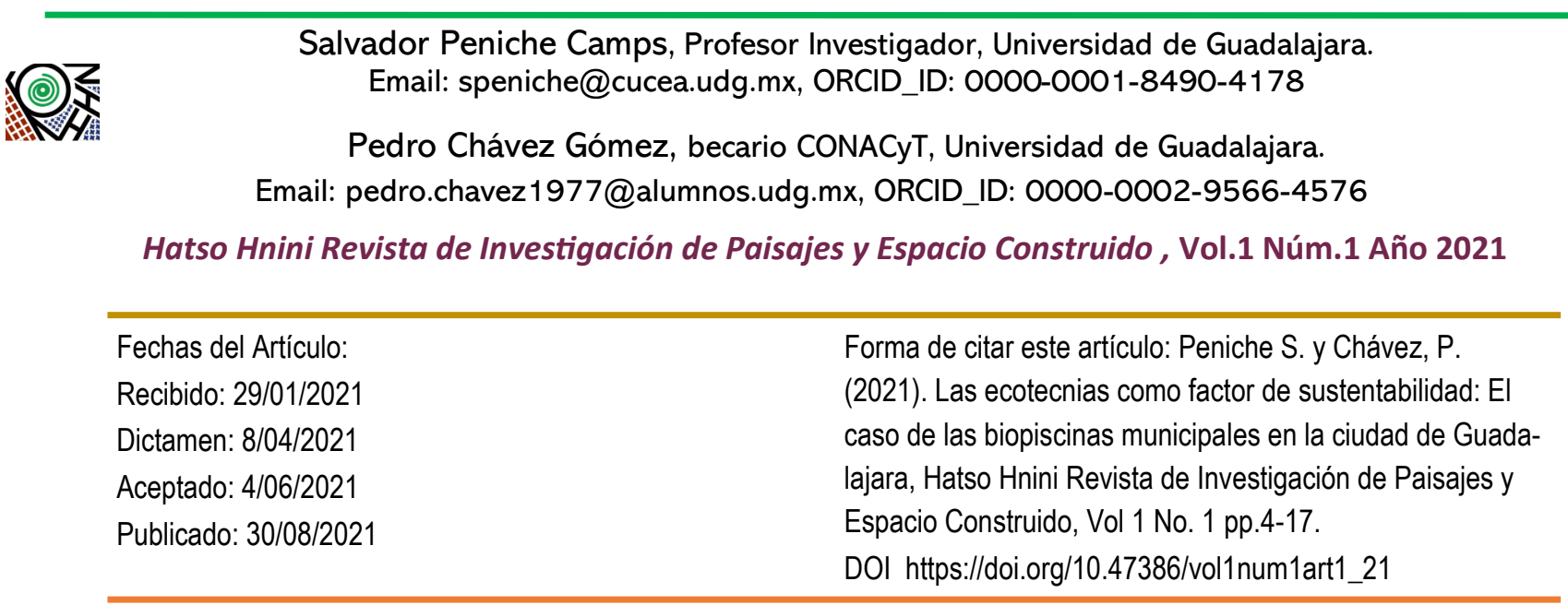

\section{Resumen}

Las ecotecnias constituyen uno de los elementos fundamentales para la construcción de condiciones para la sustentabilidad ya que representan una opción viable para enfrentar con éxito la problemática social, económica y ambiental que caracteriza a la sociedad contemporánea. El artículo que se presenta analiza el caso de las biopiscinas en la ciudad de Guadalajara y tiene el objetivo de demostrar, en el caso de estudio, su viabilidad socioambiental y económica. En particular se calcula el beneficio económico y socioambiental, no sólo para los usuarios del servicio de albercas, sino para la población, la salud ambiental y la gestión gubernamental. Con el marco teórico de la economía ecológica adaptamos el modelo costo beneficio tradicional, incorporando variables no mercantiles que permiten una valoración socioambiental de la implementación de la ecotecnia. Los resultados obtenidos, el ahorro de $\$ 177^{\prime} 660,498$ pesos anuales y la consecuente eliminación de la contaminación química en las albercas, nos permiten concluir que, en caso de aplicarse, la ecotecnia propuesta traería beneficios a los usuarios, a la población y al gobierno municipal.

Palabras clave: economía ecológica, biomímesis, racionalidad ecológica, servicios ambientales, costo beneficio .

\section{Abstract}

Ecotechnics constitute one of the fundamental elements for the construction of conditions for sustaina- bility since they represent a viable option to successfully face the social, economic and environmental problems that characterize contemporary society. The article that is presented analyzes the case of biopools in the city of Guadalajara and has the objective of demonstrating, in the case study, their socioenvironmental and economic viability. In particular, the economic and socio-environmental benefit is calculated, not only for the users of the swimming pool service, but also for the population, environmental health and government management. With the theoretical framework of ecological economics, we adapt the traditional cost-benefit model, incorporating nonmarket variables that allow a socio-environmental assessment of the implementation of eco-technology. The results obtained, the annual savings of $\$$ $17,660,498$ pesos and the consequent elimination of chemical contamination in the pools, allow us to conclude that, if applied, the proposed eco-technology would bring benefits not only for the users, but also for the population and the municipal government.

Keywords: ecological economics, biomímesis, ecological rationality, ecological rationality, cost benefit analysis .

\section{Introducción}

La cuestión del diseño e implementación de ecotecnias se encuentra en el corazón del problema de la sustentabilidad. Responde a la interrogante sobre la posibilidad de compatibilizar la actividad productiva de la sociedad con los límites biofísicos de la naturaleza. 
Las ecotecnias como factor de sustentabilidad. El caso de las biopiscinas municipales en la ciudad de Guadalajara Salvador Peniche Camps, Pedro Chávez Gómez

Hatso Hnini Revista de Investigación de Paisajes y Espacio Construido

Vol.1 Núm.1 Año 2021

El estudio que se presenta aborda el problema desde una perspectiva teórica crítica, la economía ecológica, que plantea la posibilidad de avanzar hacia la sustentabilidad a través, entre otras cosas, de la transición tecnológica ecosensible. Si consideramos que la crisis ambiental de la actualidad es causada fundamentalmente por a la utilización de tecnologías agresivas al medio ambiente, las ecotecnias, basadas en la racionalidad ecológica, es decir, inspiradas en el funcionamiento de los procesos naturales, constituyen una alternativa para conseguir los objetivos del desarrollo en armonía con las leyes de la naturaleza.

En el trabajo que se presenta proponemos la filtración natural para la limpieza de las piscinas municipales como solución a los problemas relacionados con la contaminación del agua, con la proliferación de enfermedades de los usuarios y con el desbalance presupuestario en los municipios. Consideramos que esta ecotecnia cumple con las condiciones de racionalidad ecológica y por lo tanto, constituye una opción viable para frenar los procesos disruptivos socioambientales que se derivan de la utilización de toda una serie de agentes químicos que se usan cotidianamente en las albercas municipales de la zona de estudio.

Consecuentemente, el objetivo de artículo que presentamos consiste en demostrar la viabilidad ecológica, económica y social del uso de la ecotecnia señalada. Partimos de la hipótesis de que la utilización de desinfectantes naturales garantizará un mejor desempeño del sistema de piscinas municipales tanto desde el punto de vista financiero, como en la seguridad para los usuarios y la reducción de la contaminación del agua.

El trabajo consta de los siguientes apartados: la primera sección, intitulada "La economía ecológica de las ecotecnias", se explora el concepto de ecotecnia en el contexto teórico económico ecológico y a partir de la crítica a las concepciones dominantes sobre la sustentabilidad. En el segundo apartado, "Limpieza de las piscinas municipales de la ciudad de Guadalajara: cloro vs filtración natural" se expone el caso de estudio. En la tercera parte, "El modelo costo- beneficio socioambiental", se describe la metodología utilizada. Al final del trabajo se exponen las conclusiones correspondientes.

\section{La economía ecológica de las ecotecnias}

¿Debemos entender la destrucción del medio ambiente como resultado inevitable del progreso? El sentido de la respuesta a tan fundamental interrogante nos ubica en uno de los dos campos teóricos opuestos, relativos a la sustentabilidad.

Por un lado, está la visión dominante que pone énfasis en el imperativo del crecimiento económico. Ciertamente, en los objetivos de desarrollo sostenible de las Naciones Unidas, el crecimiento económico figura como una de las prioridades en el camino hacia la sustentabilidad.

Así, en el objetivo 8.1 se lee:

"Mantener el crecimiento económico per cápita de conformidad con las circunstancias nacionales y, en particular, un crecimiento del producto interno bruto de al menos el $7 \%$ anual en los países menos adelantados" (ONU, 2021).

Desde la perspectiva económica tradicional, la generación de la riqueza social constituye la condición sine qua non para la obtención de la sustentabilidad $y$, consecuentemente, el surgimiento de problemas socioambientales es considerado el resultado de fallas de mercado o externalidades. En este sentido se plantea que la generación acelerada de riqueza social hará posible la construcción de sociedades sustentables. Para enfrentar las ineficiencias del mercado (que generan afectaciones ambientales), la política oficial sugiere la aplicación de medidas de gestión "ambiental" destinadas a la "internalización de las externalidades", es decir, la recuperación de los equilibrios que permiten la utilización eficiente de los recursos. Se sugiere que la mejor manera de mejorar las condiciones ambientales consiste en la procuración de eficiencias económicas.

Bajo esta perspectiva teórica, se han diseñado e implementado "tecnologías verdes" tales como los biocombustibles o los nuevos procesos ahorradores de recursos naturales (como el riego por goteo o la ge- 
Las ecotecnias como factor de sustentabilidad. El caso de las biopiscinas municipales en la ciudad de Guadalajara Salvador Peniche Camps, Pedro Chávez Gómez

Hatso Hnini Revista de Investigación de Paisajes y Espacio Construido

Vol.1 Núm.1 Año 2021

neración de organismos genéticamente modificados).

En el otro lado del espectro ambientalista se encuentran las teorías heterodoxas que consideran la posibilidad de compatibilizar las fuerzas productivas con los límites naturales de los cuales depende la sociedad en su conjunto. La clave para la obtención de la sustentabilidad, según esta perspectiva, consiste en desvincular la sustentabilidad con el crecimiento económico.

Lo anterior fue planteado por uno de los padres de la economía ecológica, Robert Daly, quien propuso el concepto de la "Economía de estado estacionario":

Para la economía de estado estacionario, la visión pre analítica es que la economía es un subsistema abierto de un ecosistema finito $y$ no creciente (el medio ambiente). La economía vive imponiendo materia-energía de baja entropía (materias primas) y exportando materia-energía de alta entropía (desperdicio). Cualquier subsistema de un sistema finito que no crece debe en algún momento también volverse no creciente. En alguna escala óptima, o al menos sostenible, el subsistema económico debe mantenerse en un estado estable en la medida de lo posible. (Daly, 1977, p. xiii)

De esa manera, desde la perspectiva de la economía ecológica y otras corrientes heterodoxas, la clave consiste en poner en el centro de la racionalidad productiva el imperativo ecológico. La política ambiental debe consistir, entonces, en promover la transición hacia un nuevo modelo de producción y de consumo compatible con las leyes de la naturaleza. En el centro de esta estrategia se encuentra el diseño de la nueva tecnología para la sustentabilidad: las ecotecnias.

No basta con que una nueva tecnología o proceso puedan ahorrar materiales o energía. Lo importante es abandonar lo que Marcuse denominó la "racionalidad tecnológica" de la sociedad industrial, es decir la lógica en la que se diseña y aplica la tecnología en el sistema de mercado: ...el aparato impone sus exigencias económicas y políticas para expansión y defensa sobre el tiempo de trabajo y el tiempo libre, sobre la cultura material e intelectual. En virtud de la manera en que ha organizado su base tecnológica, la sociedad industrial contemporánea tiende a ser totalitaria. Porque no es sólo "totalitaria» una coordinación política terrorista de la sociedad, sino también una coordinación técnico-económica no-terrorista que opera a través de la manipulación de las necesidades por intereses creados, impidiendo por lo tanto el surgimiento de una oposición efectiva contra el todo. (Marcuse, 1954, p. 33)

En este sentido, las ecotecnias para la sustentabilidad deben apoyarse en una nueva racionalidad (Leff, 2004), la ecología profunda de Capra (1996), y constituirse como instrumentos de producción que, además de mantener los balances económicos, garanticen los equilibrios ecológicos de la naturaleza, emulándola (Riechmann, 2008).

De esta manera, la bioeconomía o disciplina que trata de las características productivas para la sustentabilidad, no sólo debe basarse en la eficiencia en la utilización de los recursos naturales, sino en la biomímesis o copia de los procesos productivos naturales. De lo contrario, de centrarse tan sólo en la eficiencia, las llamadas tecnologías verdes o ahorradoras, se convierten a la larga, como lo señaló Jevons, en instrumentos de sobreexplotación de recursos naturales: "Es la mismísima economía de su uso que conduce a su consumo extensivo" (Jevons, 1866, p. 124)

En resumen, el diseño de la tecnología apropiada para hacer frente al colapso ambiental de la humanidad debe ser económicamente viable, socialmente pertinente y ambientalmente sustentable.

Limpieza de las piscinas municipales de la ciudad de Guadalajara: cloro vs filtración natural

La práctica masiva de la natación genera importantes beneficios sociales para la salud física y mental de la población (Navarro, 1990; Morales, 2010). 
Las ecotecnias como factor de sustentabilidad. El caso de las biopiscinas municipales en la ciudad de Guadalajara Salvador Peniche Camps, Pedro Chávez Gómez

Hatso Hnini Revista de Investigación de Paisajes y Espacio Construido

Vol.1 Núm.1 Año 2021

Por ello, el buen funcionamiento del sistema de albercas públicas constituye un reto importante para las autoridades. Sin embargo, para obtener los resultados deseados, es necesario contar con instalaciones en condiciones óptimas de seguridad e higiene, ya que en las albercas interactúa una gran cantidad de personas por día y, de no actuar con responsabilidad, podrían convertirse en un foco de infecciones.

Para mantener desinfectadas las piscinas ha predominado el método de cloración del agua desde hace más de cien años (Sánchez, 2011). Este método, que requiere el acompañamiento de otros productos químicos y un monitoreo constante durante el día, de no contar con el mantenimiento adecuado puede generar problemas de salud como los que se han presentado en las piscinas del Área Metropolitana de Guadalajara: el mal estado de calidad de agua de las piscinas en la ciudad ha ocasionado problemas a nadadores profesionales, quienes, como ejemplo de lo anterior, presentaron alergias y lesiones por intoxicación durante el Campeonato Nacional Curso Corto con sede en Guadalajara en diciembre de 2018. Como es sabido, la situación descrita ocasionó la suspensión de actividades relacionadas a las disciplinas acuáticas en Jalisco por parte de la Federación Mexicana de Natación. (Peña, 2018; El Universal, 2019)

El cloro se aplica ampliamente como desinfectante en superficies y en sistemas de almacenamiento y suministro de agua potable. Su popularidad se debe a su efectividad para eliminar agentes infecciosos, su fácil aplicación y bajo costo en comparación con otros productos y técnicas de purificación de agua. (Noval, 2017)

El modelo dominante actual sobre mantenimiento de albercas urbanas consiste en crear vasos de agua estériles, utilizando técnicas fisicoquímicas (cloro, floculante, nivelador de $\mathrm{pH}$, alguicidas) que eliminan cualquier organismo vivo capaz de transmitir enfermedades, dañando con esto a los propios bañistas, a los instructores de natación, el personal de mantenimiento y a numerosas especies animales y vegetales. Lo anterior ha sido considerado como un factor de pérdida de los servicios ecosistémicos necesarios para la sociedad. (Geraldes et al., 2014)

Numerosos estudios demuestran los riesgos a la salud que provoca la exposición a estas sustancias:

El cloro, además de desinfectar, reacciona con los compuestos orgánicos presentes en el agua, produciéndose productos potencialmente peligrosos para la salud, conocidos como subproductos de la desinfección (DPBs en terminología internacional). Estos DBPs entran al organismo por tres vías: ingestión de agua, inhalación y contacto dermal. Los más importantes son los trihalometanos, de entre los que destaca el cloroformo, y las cloraminas, principalmente la tricloramina... Así, diversos estudios relacionan la asistencia a piscinas cloradas con la prevalencia de jadeos, asma y fiebre del heno, lo que ha dado lugar a enunciar la "Hipótesis del cloro": postula que el aumento de asma en el mundo desarrollado puede ser debido a la exposición de los niños a los DBPs que contaminan el aire de las piscinas cubiertas. Además, y por primera vez, ha sido aceptado el asma inducido por los DBPs como una enfermedad laboral en trabajadores de piscinas. (Llana et al., 2009, p. 223).

Además del asma inducido por los DBPs, los usuarios de las piscinas tratadas convencionalmente pueden tener otros efectos genotóxicos, es decir, mutaciones en el ADN que pueden causar cáncer de vejiga. (Sánchez, 2011)

Desde la perspectiva de la economía neoclásica, el cloro es un producto eficiente para lograr la desinfección en las piscinas, por los bajos costos de producción y altos márgenes de utilidad. Sin embargo, para temar decisiones socialmente pertinentes, es necesario valorar los costos ocasionados por los problemas ambientales y de salud de los bañistas y trabajadores.

Como alternativa se plantea el modelo de piscinas biológicas, las cuales imitan a la naturaleza en el proceso de la purificación de agua. Lo anterior se 


\section{Salvador Peniche Camps, Pedro Chávez Gómez}

Hatso Hnini Revista de Investigación de Paisajes y Espacio Construido

Vol.1 Núm.1 Año 2021

efectúa por medio de especies vegetales y animales sis con zooplancton y microorganismos para eliminar que depuran el agua y controlan la proliferación de bacterias, virus y diversos contaminantes, absorben posibles microorganismos patógenos. De ser contro- el exceso de materia orgánica creando biomasa por lados correctamente los procesos biofísicos, esta medio de fotosíntesis y son un alguicida eficaz: ecotecnia representa una opción más eficiente desde el punto de vista económico, social y ambiental con respecto al método tradicional.

Los procesos físicos, químicos y biológicos en las piscinas ecológicas se asemejan al proceso de autodepuración de los humedales que mantiene el agua en su estado natural. El sistema constituye el tipo de piscina biológica más utilizado para uso recreativo y se caracteriza por tener un suelo saturado donde habitan microorganismos y plantas (Pérez et al., 2017).

La relación causa-efecto de los impactos a la salud en las piscinas tratadas con la tecnología convencional se observa en la figura 1.

Las plantas acuáticas son la clave para la desinfección del agua en las piscinas biológicas ya que se encargan de aumentar la oxigenación, hacen simbio-

Al aumentar el nivel de oxigenación del agua, evitan el desarrollo de microorganismos patógenos, porque generalmente prefieren entornos anaeróbicos, que no prosperan en sistemas bien oxigenados. Por otro lado, cuando el agua está bien oxigenada, permite el aumento del zooplancton. Muchas de las especies que forman parte del zooplancton son depredadores de bacterias y otros microorganismos. Otro papel importante que tienen las plantas es la eliminación del exceso de nutrientes del agua... Otros investigadores también notaron que los macrófitos eliminan de manera eficiente varios tipos de contaminantes presentes en el agua (por ejemplo, Ganjo y Khwakaram, 2010)... Las macrófitas también controlan el crecimiento excesivo de microalgas $y$ otras algas filamento-

Figura 1. Árbol de problemas de salud por clorar piscinas
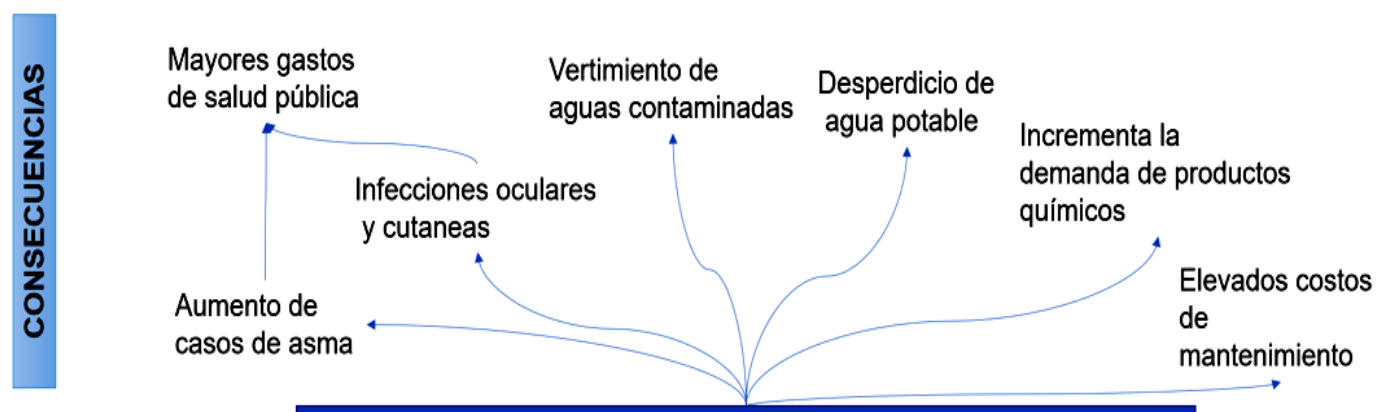

MAYOR RIESGO EN LA SALUD DE LOS NADADORES Y

OPERADORES DE PISCINAS TRATADAS CON CLORO

Alta toxicidad de los subproductos del cloro

Fácil aplicación y bajo costo de próductos químicos

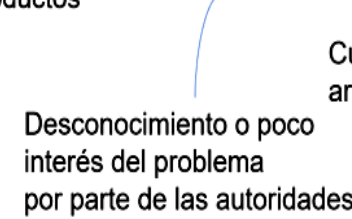

Cultura de esterilizar artificialmente el agua
Desconocimiento o poco interés por los sistemas de fitorremediación 


\section{Salvador Peniche Camps, Pedro Chávez Gómez}

Hatso Hnini Revista de Investigación de Paisajes y Espacio Construido

Vol.1 Núm.1 Año 2021

La experiencia internacional demuestra que los productos químicos no son necesarios para desinfectar una piscina. Si se colocan las plantas adecuadas y se controla la higiene previa a la entrada de los nadadores (ducharse para remover productos químicos como perfume, bloqueador, etc.), se logran estándares de calidad de agua del tipo de los que existen en una laguna o humedal. Además, las plantas tienen una ventaja significativa sobre los sistemas de depuración convencionales: aumentan la biodiversidad. En estos estanques recreativos naturales se han encontrado gran variedad de insectos, anfibios, reptiles, aves y mamíferos acuáticos.

Por otra parte, las piscinas biológicas absorben grandes cantidades de $\mathrm{CO}_{2}$ de la atmósfera, contribuyen a mejorar la calidad del aire y proporcionan un paisaje natural que crea un valor estético y espiritual, contrario al ambiente estéril de las piscinas convencionales (Geraldes et al., 2014).

La relación de las soluciones que plantea la utilización de la ecotecnia se expresa en la figura 2.

Guadalajara cuenta con 17 unidades deportivas con piscinas públicas, cuya administración es responsa- bilidad de tres organismos: el Consejo Municipal del Deporte (COMUDE-Guadalajara) que gestiona 12, el Consejo Estatal para el Fomento Deportivo (CODE), 4 y la Universidad de Guadalajara (UDG), 1.

Para poder adaptar un sistema de fitorremediación en las albercas es necesario que no tengan techo, para que las plantas que limpian el agua reciban la luz directa del sol; de las 17 piscinas correspondientes al COMUDE Guadalajara, 3 se encuentran techadas y 12 están abiertas como se aprecia en la figura 3.

Dado que en la NOM-245-SSA1-2010 no está estipulada la capacidad de carga máxima recomendada para una piscina de uso público, utilizamos como referencia los Requisitos sanitarios y calidad del agua que deben cumplir las albercas Según el Reglamento Sobre Manejo de Piscinas, Decreto $\mathrm{N}^{\circ}$ 35309-S promulgado en 2009 por el Presidente y la Ministra de Salud de la República de Costa Rica. En dicha reglamentación se estipula como máximo a 1

Figura 2. Árbol de soluciones por biopiscinas
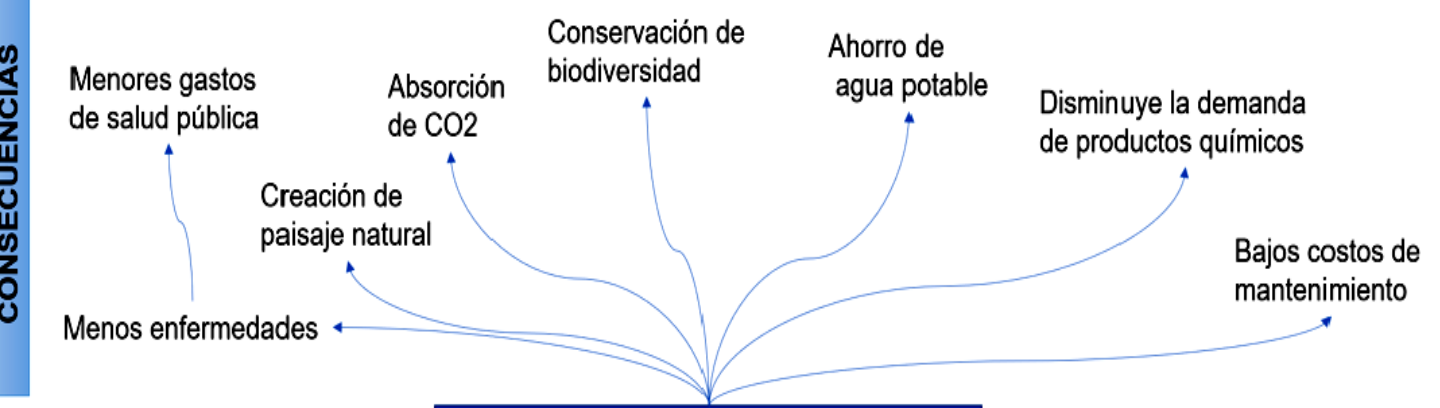

IMPLEMENTAR BIOPISCINAS

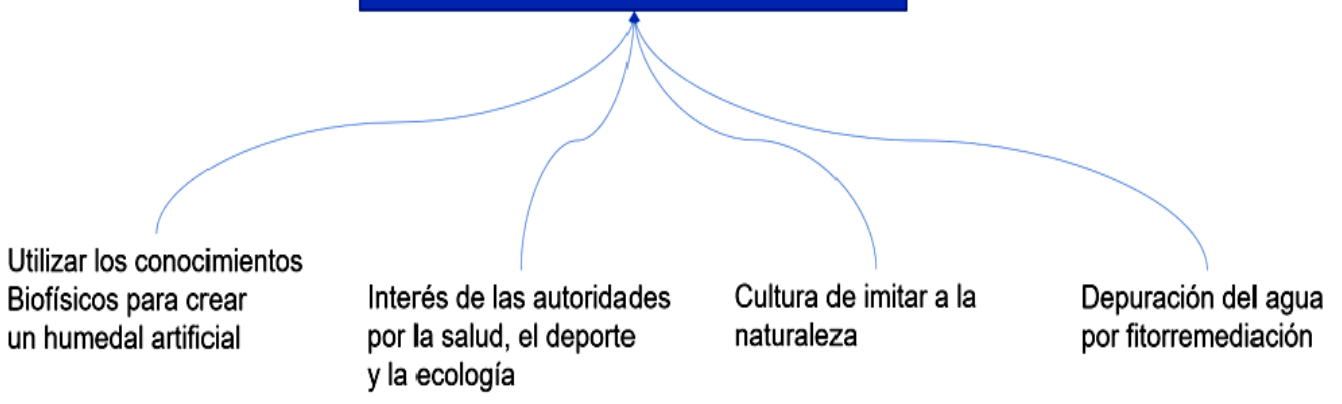

Fuente: elaboración propia con base en Sánchez, 2011; Geraldes et al., 2014; Pérez et al., 2017. 
Figura 3. Ubicación de las piscinas de COMUDE Guadalajara

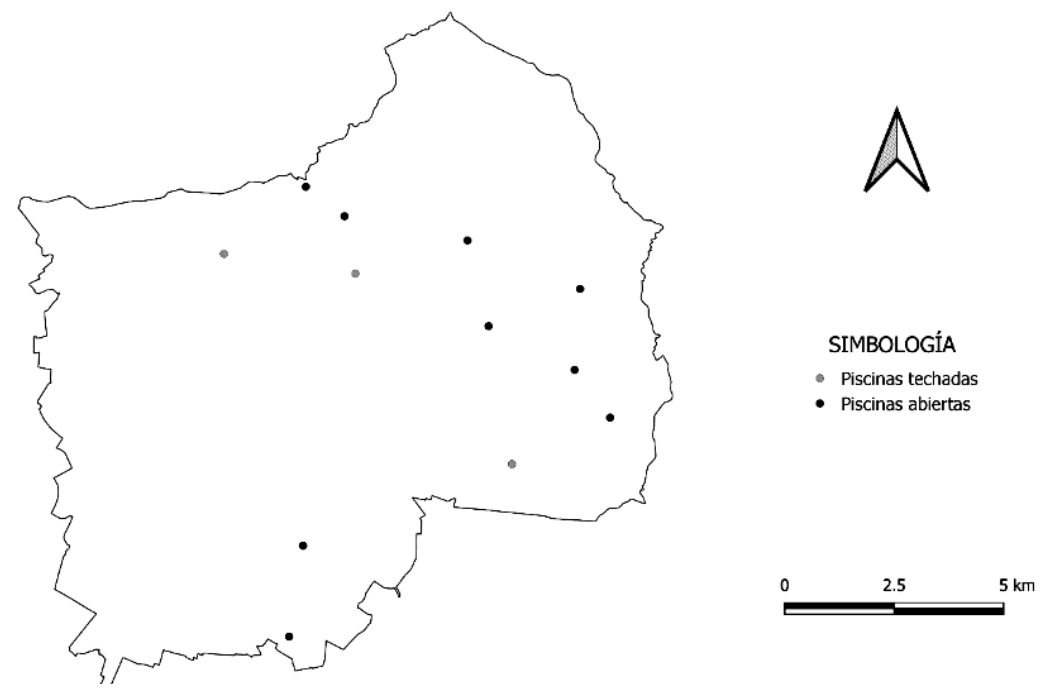

Fuente: elaboración propia a partir del modelo vectorial (Marco Geoestadístico Nacional, Versión 5.0) del INEGI, 2010.

Tabla 1. Piscinas gestionadas por COMUDE

Guadalajara

\begin{tabular}{llll}
\hline Administración & Nombre de Unidad Deportiva & Tamaño $\left.\mathbf{( m}^{2}\right)$ & Techada \\
\hline & 04 Javier Mina & 400 & No \\
& 06 Plan de Ayala & 320 & Sí \\
& 07 Héroes de Chapultepec & 350 & Sí \\
& 08 Cuauhtémoc & 350 & No \\
& 09 Plan de San Luis & 320 & No \\
COMUDE & 11 López Cotilla & 350 & No \\
Guadalajara & 12 Independencia & 350 & Sí \\
& 13 Libertador Miguel Hidalgo & 350 & No \\
& 37 Cd. de Tucson & 320 & No \\
& 48 Prof. Manuel Uriarte Tovar & 320 & No \\
& 69 Parque Liberación & 350 & No \\
& 78 Parque Centenario & 320 & No \\
\hline
\end{tabular}

Fuente: elaboración propia con base en COMUDE, 2020.

\section{El modelo costo-beneficio socioambiental}

La metodología propuesta evalúa el proceso biofísico de la depuración de las piscinas en la práctica social de los deportes acuáticos, analizando los riesgos de nadar en piscinas con tratamiento de agua por méto- dos químicos tradicionales.

El objetivo del estudio que se presenta consiste en determinar la viabilidad económica de implementar sistemas de depuración biológicos en las 9 piscinas aptas administradas por el COMUDE Guadalajara. 
Las ecotecnias como factor de sustentabilidad. El caso de las biopiscinas municipales en la ciudad de Guadalajara Salvador Peniche Camps, Pedro Chávez Gómez

Hatso Hnini Revista de Investigación de Paisajes y Espacio Construido

Vol.1 Núm.1 Año 2021

Se considera que de ser rentables la aplicación de La aplicación de productos químicos es el método de esta ecotecnia contribuiría a evitar los problemas de mantenimiento de albercas más utilizado en el munsalud en los usuarios y operadores causados por la do. Para mantener las condiciones de calidad que exposición a los productos químicos convencionales. estipula la Norma Oficial Mexicana es necesario traAdemás, la utilización de este sistema permitiría el tar el agua con cloro, floculante, alguicida y reductor ahorro de recursos financieros del gobierno municipal a largo plazo y a crear patrimonio natural.

La contribución de este estudio consiste en establecer los beneficios económicos, sociales y ecológicos de la ecotecnia, para proponer el cambio de sistemas convencionales de depuración de agua por sistemas naturales en las piscinas municipales. Lo anterior con la idea de que sirva de ejemplo para aplicar a las demás piscinas públicas o privadas que se encuentran en el Área Metropolitana de Guadalajara. El estudio aporta elementos que permiten valorar económicamente la depuración ecológica del agua y vincular las actividades deportivas con la gestión sostenible de la naturaleza. Con esta información, los tomadores de decisiones podrán decidir sobre los proyectos municipales en materia de albercas y decidir si es más viable continuar con métodos químicos que representan un riesgo a la salud para los usuarios, un deterioro ambiental y un mayor gasto financiero para el gobierno local o adoptar la ecotecnia propuesta por el estudio.

de $\mathrm{pH}$. El cloro funciona como un potente desinfectante de virus, bacterias, algas y hongos, se aplica diariamente y su dosis varía dependiendo la cantidad de usuarios; el reductor de $\mathrm{pH}$ regula la acidez del agua, factor clave para que el cloro cause su efecto desinfectante; El alguicida evita la proliferación de fitoplancton y algas microscópicas con rápidos ritmos reproductivos y el floculante hace que las partículas pequeñas suspendidas en el agua se unan, creando partículas de mayor tamaño y sean capturadas en los filtros mecánicos (Mapfre, 2007).

Además de los procesos mencionados líneas arriba, existen sistemas como los que proponemos, que emulan a los sistemas de limpieza que ocurren en la naturaleza. Estos sistemas de filtración natural disminuyen el impacto ambiental en comparación con las piscinas convencionales: $y$, por medio del ciclo del nitrógeno, eliminan el exceso de materia orgánica que introducen los bañistas. Las plantas acuáticas y el plancton son los encargados de hacer la depuración. (Sánchez, 2011).

Las piscinas de México deben cumplir con las indicaciones de la "NOM-245-SSA1-2010, Requisitos sanitarios y calidad del agua que deben cumplir las albercas" para poder operar garantizando un ambiente saludable a los bañistas. En la norma se describen los límites permisibles de los principales parámetros fisicoquímicos (temperatura, $\mathrm{PH}$, alcalinidad, dureza, materia orgánica) y microbiológicos para cumplir los requisitos sanitarios (DOF, 2012).

Para cumplir con los requisitos anteriores los propietarios o responsables del mantenimiento de las piscinas han aplicado diversos métodos, como la recirculación (con filtros de cartucho, de diatomeas, de arena, bicapa, multicapa, etc.), la aplicación de sales minerales, luz ultravioleta y productos químicos; siendo los últimos los más utilizados a nivel internacional por su efectividad para eliminar virus y bacterias a menor costo en comparación con los otros sistemas.

\section{Cálculo económico}

En el presente apartado se valora el tiempo de retorno de la inversión inicial si se adaptan 9 biopiscinas del COMUDE Guadalajara. Se calculó el Valor Actual Neto (VAN) y la Tasa Interna de Retorno (TIR) para determinar la factibilidad de dejar de utilizar productos químicos para el mantenimiento de las piscinas.

Para decidir la aprobación o rechazo de un proyecto de inversión pública se ha utilizado preferentemente el Análisis Costo Beneficio (ACB), como un instrumento financiero fiable. (Adam et al., 2003)

EI ACB funciona valorando monetariamente la comparación entre el costo del proyecto y su beneficio, lo que permite conocer en cuanto tiempo se amortiza la inversión. (Henderson y Bateman, 1995). 
Las ecotecnias como factor de sustentabilidad. El caso de las biopiscinas municipales en la ciudad de Guadalajara Salvador Peniche Camps, Pedro Chávez Gómez

\section{Hatso Hnini Revista de Investigación de Paisajes y Espacio Construido}

Vol.1 Núm.1 Año 2021

Los primeros $A C B$ se utilizaban en obras gubernamentales para evaluar proyectos que no requerían el nivel de rentabilidad de las empresas y cuyo único requisito era que se amortizara la inversión en un determinado periodo de tiempo. Sin embargo, el concepto fue evolucionando y en la actualidad se busca que el proyecto, además de recuperar la inversión, pueda mantener el servicio por medio de una contribución. (Baca, 2013)

Considerando lo anterior, calculamos el VAN y la TIR para las nueve piscinas del COMUDE Guadalajara. Lo anterior se debe a que dichos cálculos contemplan un flujo de caja, el cual representa el ahorro del gasto en productos químicos.

EI VAN es una herramienta que expresa el beneficio producido por un proyecto de inversión durante su vida útil. Con la ayuda de una tasa de descuento, el índice determina la diferencia entre la inversión inicial y los flujos de efectivo equivalentes al tiempo presente. Si el resultado del cálculo resulta un número positivo se recomienda aceptar el proyecto. El cálculo del VAN se obtiene con la siguiente fórmula (Baca, 2013):

$$
V A N=-I_{0}+\frac{F_{1}}{(1+k)}+\frac{F_{2}}{(1+k)^{2}}+\cdots+\frac{F_{n}}{(1+k)^{n}}
$$

Donde:

$\mathrm{I}_{0}=$ Inversión inicial

$\mathrm{F}=$ Flujo neto de efectivo

$\mathrm{k}=$ Tasa de descuento

$\mathrm{n}=$ Periodos de vida útil del proyecto

Cuando igualamos el VAN a $0, \mathrm{k}$ se convierte en la TIR que representa la rentabilidad del proyecto (en porcentaje). En este caso el VAN se calcula con la siguiente fórmula (Baca, 2013):

$$
V A N=\sum_{t=1}^{n} \frac{F_{t}}{(1+T I R)^{t}}-I=0
$$

Donde:

$F_{t}=$ flujo de caja en el periodo $t$.

$$
\begin{aligned}
& \mathrm{I}=\text { Inversión inicial. } \\
& \mathrm{n}=\text { cantidad de periodos. }
\end{aligned}
$$

Para determinar la cantidad de productos químicos utilizados se consultaron empresas dedicadas al mantenimiento de albercas convencionales y de biopiscinas, las cuales informaron que para las nueve piscinas se requieren aproximadamente $\$ 900,840.00$ pesos al mes en productos químicos para depuración del agua, utilizando sustancias como cloro, reductor de $\mathrm{pH}$, alguicida y floculante (tabla 2).

Por su parte, adaptar las piscinas de estudio con un sistema natural tiene un costo de $\$ 28,336,000.00$ de pesos en su máxima capacidad de 10,260 usuarios al día.

Se obtuvieron el VAN y la TIR con base a la inversión inicial de $\$ 28$ '336,000 de pesos y con una tasa de descuento del $0.07 \%$ arrojando el siguiente resultado: la aplicación de la ecotecnia generará un ahorro de $\$ 10$ '810,080 de pesos en productos químicos anuales, considerando que el tiempo de vida promedio de una piscina es de 25 años:

$$
\begin{gathered}
V A N=-28^{\prime} 336,000+\frac{10^{\prime} 810,000}{(1+0.07)}+\frac{10^{\prime} 810,000}{(1+0.07)^{2}}+ \\
\ldots+\frac{10^{\prime} 810,000}{(1+0.07)^{25}}=97^{\prime} 639,235
\end{gathered}
$$

Los cálculos del VAN y la TIR con base a la inversión inicial de $\$ 28$ '336,000 de pesos y con una tasa de descuento del $0.07 \%$ arrojaron los siguientes resultados: la aplicación de la ecotecnia generará un ahorro de $\$ 10$ '810,080 de pesos en productos químicos anuales, considerando que el tiempo de vida promedio de una piscina es de 25 años.

Como puede observarse, la aplicación del modelo es viable ya que el VAN es positivo e igual a 97'639,235 y la TIR es mayor que la tasa de descuento, $38.14 \%$ $>0.07 \%$.

Con la información anterior se observa que el proyecto es significativamente rentable porque la inversión retornaría al tercer año aproximadamente, generando un ahorro en productos químicos de 97'639,235 pesos, al finalizar los 25 años de vida del proyecto. 
Las ecotecnias como factor de sustentabilidad. El caso de las biopiscinas municipales en la ciudad de Guadalajara Salvador Peniche Camps, Pedro Chávez Gómez

Hatso Hnini Revista de Investigación de Paisajes y Espacio Construido

Vol.1 Núm.1 Año 2021

Tabla 2. Consumo de productos químicos para el mantenimiento de las nueve piscinas abiertas
del
$\begin{array}{llllll}\text { Productos } & \text { Costo } & \text { Consumo } & \text { Costo } & \text { Consumo } & \text { Costo } \\ \text { químicos } & \text { Unitario } & \text { Mensual } & \text { Mensual } & \text { Anual } & \text { Anual } \\ & (\text { pesos } / \mathrm{kg}) & (\mathrm{kg}) & \begin{array}{l}\text { (pesos) } \\ (\mathrm{kg})\end{array} \\ \text { Cloro } & 80 & 6,468 & 517,440 & 77,616 & 6,209,280 \\ \text { Reductor de pH } & 90 & 2,064 & 185,760 & 24,768 & 2,229,120 \\ \text { Alguicida } & 180 & 400 & 72,000 & 4,800 & 864,000 \\ \text { Floculante } & 120 & 1,047 & 125,640 & 12,564 & 1,507,680 \\ \text { Total } & & 9,979 & 900,840 & 119,748 & 10,810,080\end{array}$
Fuente: elaboración propia con base a información proporcionada por Huul Kiin, 2020.

Figura 4. Periodo de amortización al implementar nueve biopiscinas en el COMUDE Guadalajara

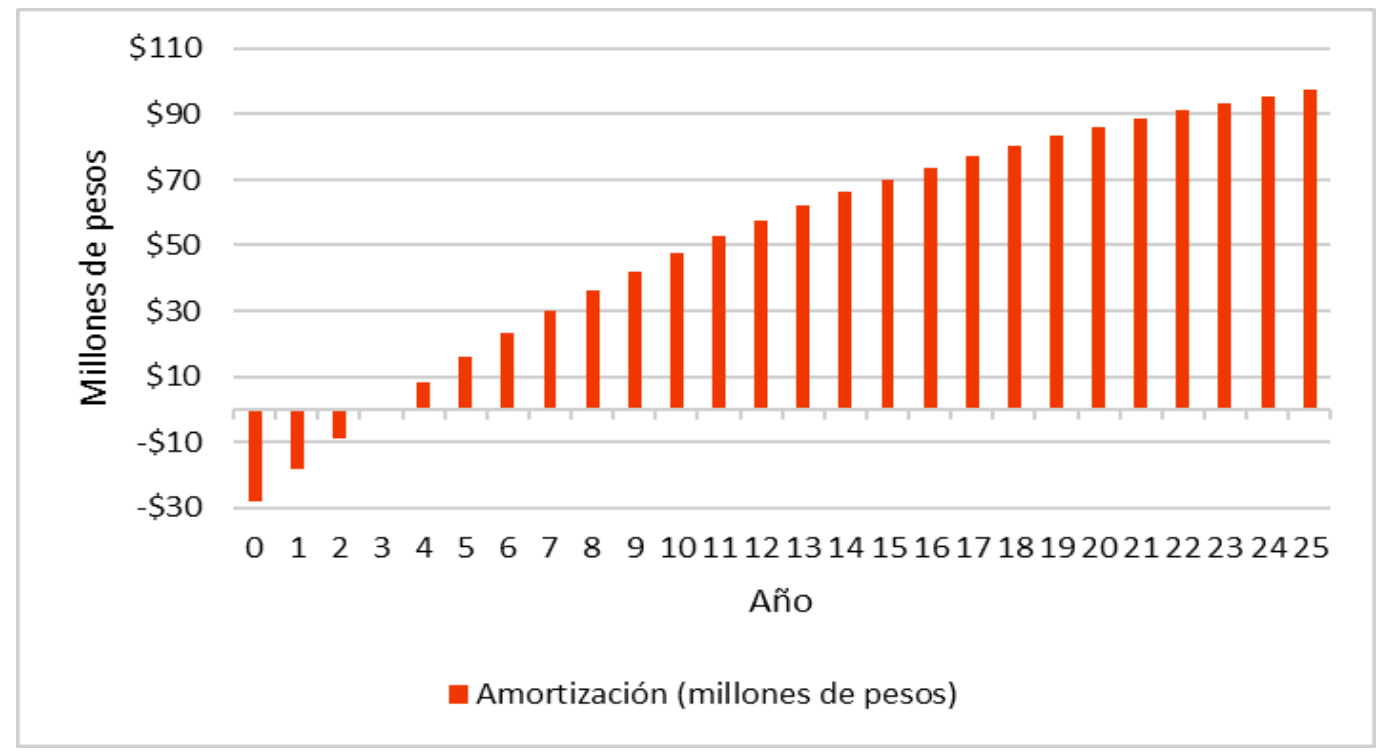

Fuente: elaboración propia con base en Baca, 2013; Huul Kiin, 2020.

\section{Valoración socioambiental}

El estudio económico del apartado anterior se centra únicamente en monetizar los beneficios del sistema de mantenimiento de una biopiscina al ahorrar insumos (productos químicos) y conocer el periodo de amortización de la inversión necesaria, así como el margen de ganancia financiera que genera a largo plazo. Pero ¿qué sucede con el estudio económico al monetizar también los beneficios socioambientales de la biopiscina?

El problema más importante que se evitaría al dejar de utilizar cloro es el asma inducido por los subproductos que se generan. En un estudio publicado por Helenius y Haahtela (2000) encontraron que el $21 \%$ de nadadores profesionales mostraron incidencia de asma. Los costos derivados de la atención médica 
Las ecotecnias como factor de sustentabilidad. El caso de las biopiscinas municipales en la ciudad de Guadalajara Salvador Peniche Camps, Pedro Chávez Gómez

Hatso Hnini Revista de Investigación de Paisajes y Espacio Construido

Vol.1 Núm.1 Año 2021

por asma ascienden en promedio a 2,900 pesos por persona por año (Gallardo et al., 2007). Considerando las premisas anteriores, si el $21 \%$ de los 10,260 nadadores que pueden visitar las piscinas del COMUDE Guadalajara desarrollan la enfermedad, es decir 2,155 personas, el costo de salud pública por año es de $\$ 6 ' 249,500.00$ pesos.

Desde la perspectiva ambiental, implementar una biopiscina contribuye al ahorro de agua. Las piscinas tratadas con productos químicos tienen que vaciarse mínimo una vez al año; para las 9 albercas del COMUDE Guadalajara lo anterior representa 4,620 m3 de de agua contaminada, desechada al drenaje; Con base a la tarifa de 15 pesos por $\mathrm{m} 3$ de agua potable vigente en la AMG (CONAGUA, 2018), el COMUDE Guadalajara tendría un ahorro de $\$ 69,300.00$ pesos al año.

Además del ahorro de agua, las biopiscinas brindan bienestar a la sociedad por medio de servicios ecosistémicos. De acuerdo con estudios realizados sobre la valoración de humedales, los cuales aportan $\$ 590,686.00$ pesos por hectárea por año, los humedales artificiales que generarían las piscinas del COMUDE Guadalajara tendrían un valor de $\$ 531,618$ pesos por año con sus 0.9 hectáreas de extensión (TEEB, 2020).

Si consideramos la monetización de los beneficios socioambientales que muestra la tabla 3 , con base a la inversión inicial de $\$ 28,336,000$ pesos, con una tasa de descuento del $0.07 \%$, la ecotecnia generará un beneficio de $\$ 17 ' 660,498$ pesos anuales deriva- dos de 1) el ahorro de productos químicos y agua potable, 2) la generación de servicios ecosistémicos al crear el humedal artificial y 3) el ahorro en gastos de salud pública (al evitar los problemas de asma).

Considerando que el tiempo de vida promedio de

$$
\begin{aligned}
& V A N=-28^{\prime} 336,000+\frac{17^{\prime} 660,498}{(1+0.07)}+\frac{17^{\prime} 660,498}{(1+0.07)^{2}}+ \\
& 25 \text { años } \ldots+\frac{17^{\prime} 660,498}{(1+0.07)^{25}}=177^{r} 472,082 \text { se obtiene } \\
& \text { un VAN y una TIR } \\
& T I R=62.32 \%
\end{aligned}
$$

Los cálculos nos permiten concluir sobre la viabilidad del proyecto ya que el VAN se incrementa de $97^{\prime} 639,235$ a $177^{\prime} 472,082$, y el TIR de $38.14 \%$ a $62.32 \%$.

Con la información anterior se observa que el proyecto es significativamente rentable ya que los cálculos demuestran que la inversión retornaría antes de los 2 años aproximadamente, generando un beneficio económico de $177^{\prime} 472,082$ pesos al finalizar los 25 años de vida del proyecto. Además, representa un menor impacto socioambiental al no contaminar con residuos tóxicos, al evitar el desperdicio de agua por mantener el agua en las piscinas anualmente, al crear servicios ecosistémicos como la con-

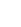

\begin{tabular}{lcc}
\hline \multicolumn{1}{l}{ Tabla 3. Valor total de implementar las } & $\mathbf{9}$ biopiscinas en el COMUDE Guadalajara \\
\hline & Costo & Costo \\
Valor Total & $\begin{array}{l}\text { Mensual } \\
\text { (pesos) }\end{array}$ & Anual \\
(pesos) \\
Productos químicos & 900,840 & $10,810,080$ \\
Atención por asma & 520,792 & $6,249,500$ \\
Ahorro de agua potable & 5,775 & 69,300 \\
Servicios ecosistémicos & 44,302 & 531,618 \\
Total & $1,471,708$ & $17,660,498$ \\
Fuente: elaboración propia, con base en Huul Kin, 2020; Gallardo et al., 2007; CONAGUA, 2018; TEEB, 2020. \\
\hline
\end{tabular}


Las ecotecnias como factor de sustentabilidad. El caso de las biopiscinas municipales en la ciudad de Guadalajara Salvador Peniche Camps, Pedro Chávez Gómez

Hatso Hnini Revista de Investigación de Paisajes y Espacio Construido

Vol.1 Núm.1 Año 2021

Figura 5. Periodo de amortización en las 9 piscina de COMUDE Guadalajara considerando el valor de los beneficios socioambientales

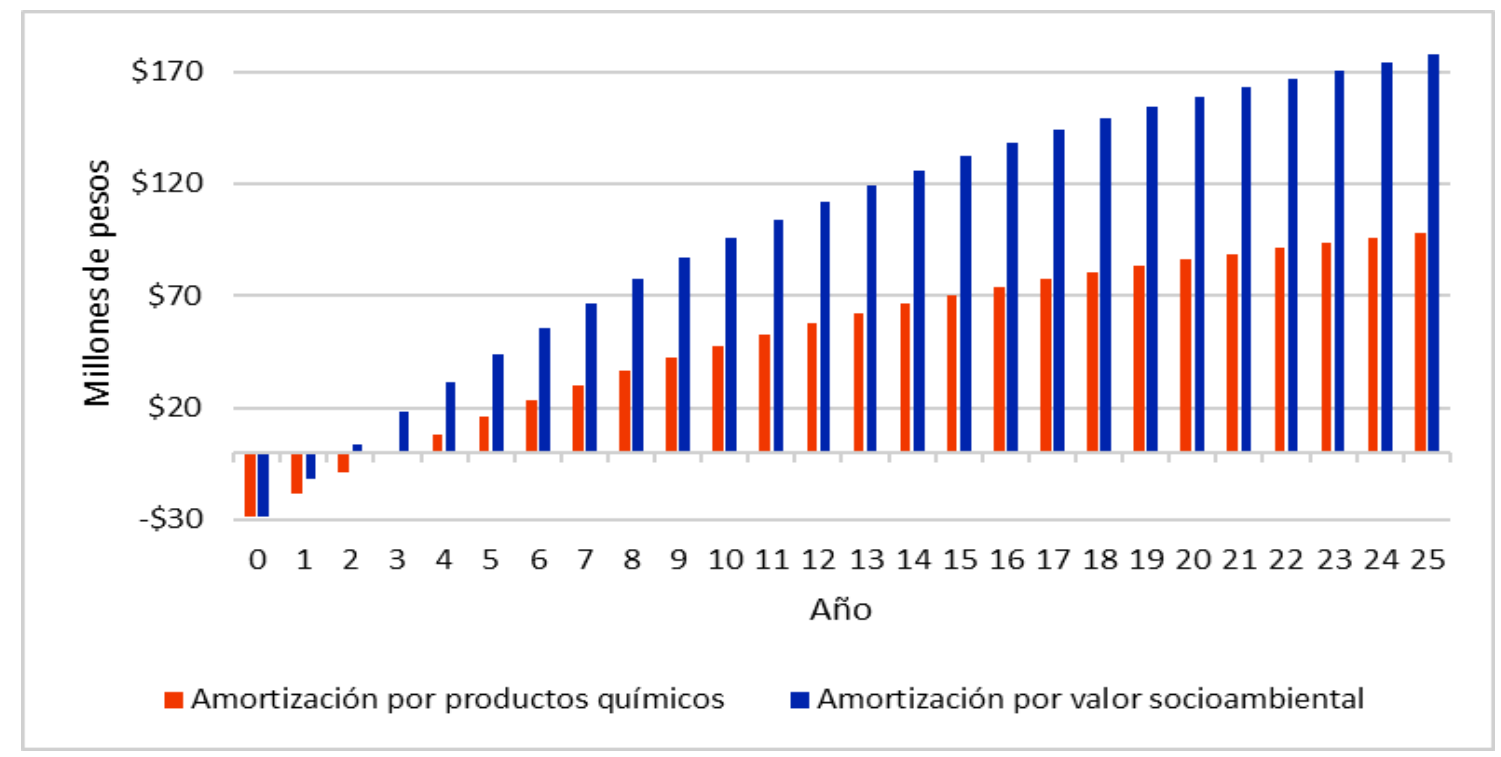

Fuente: elaboración propia, con base en Baca, 2013; Huul Kiin, 2020; Gallardo et al., 2007; CONAGUA, 2018; TEEB, 2020.

servación de biodiversidad y paisaje natural, y lo que se considera más relevante, el evitar los problemas de salud por el asma que producen los subproductos del cloro.

\section{Conclusiones}

La filtración natural puede considerarse una ecotecnia en el sentido de la economía ecológica ya que cumple con las precondiciones propuestas de viabilidad económica, pertinencia social y sustentabilidad ambiental.

A diferencia del sistema depurador biológico que no causa ningún efecto secundario en los nadadores porque cumple con los estándares de calidad de agua (si se respeta la capacidad de carga y se controlan los parámetros fisicoquímicos necesarios), utilizar productos químicos para limpiar las piscinas puede causar problemas de salud para los bañistas y para los ecosistemas donde se extraen las materias primas y en los que se vierten los residuos contaminantes.

Implementar las nueve biopiscinas en COMUDE Guadalajara requiere una inversión de \$28,336,000 pesos, la cual se recupera aproximadamente en me- nos de 2 años debido al ahorro de $\$ 17^{\prime} 660,498$ pesos anuales que representa dejar de utilizar productos químicos para depurar el agua de la piscina, el ahorro del sistema de salud por los tratamientos de asma, el ahorro de agua potable al no tener que vaciar las piscinas una vez al año y la salvaguarda de los servicios ecosistémicos que proporcionan los humedales artificiales.

Sin embargo, el valor más importante de la biopiscina es inconmensurable económicamente: evitar problemas de asma en los nadadores y operadores por el contacto con los subproductos del cloro.

El municipio de Guadalajara cuenta con poca infraestructura pública para ofrecer deportes acuáticos a la población, cubriendo solo el $2.2 \%$ de usuarios si se trabajan todas las piscinas públicas a su máxima capacidad. Crear una biopiscina representa un elevado costo de inversión para su construcción, pero sus costos de mantenimiento son significativamente menores en comparación con una piscina convencional, por lo que a largo plazo representa menor gasto operativo.

Una de las desventajas de utilizar los sistemas naturales para desinfectar piscinas es que las plantas 
Las ecotecnias como factor de sustentabilidad. El caso de las biopiscinas municipales en la ciudad de Guadalajara Salvador Peniche Camps, Pedro Chávez Gómez

Hatso Hnini Revista de Investigación de Paisajes y Espacio Construido

Vol.1 Núm.1 Año 2021

tienen una capacidad de asimilación de la materia orgánica, lo que limita la cantidad de usuarios que pueden nadar al día, sin embargo, a partir de la propagación del COVID-19 a nivel mundial y local se han tomado medidas estrictas para limitar la cantidad de personas que deben interactuar en un espacio determinado, por lo tanto implementar el sistema propuesto en el estudio representa una oportunidad pertinente para las recomendaciones de distanciamiento social.

Concluimos que implementar una piscina biológica y dejar de utilizar productos químicos en las piscinas públicas representa un ahorro significativo en el proceso de desinfección del agua. El estudio demuestra que, además del ahorro financiero, con la aplicación de la ecotecnia, disminuyen significativamente los riesgos a la salud (como las afectaciones por asma, causados principalmente por la aplicación de cloro en las albercas), se crea valor paisajístico y aumenta la superficie para conservación de la biodiversidad.

\section{Referencias}

Adam, T., Evans, D.B. y Koopmanschap, M.A. (2003). Cost-Effectiveness Analysis: Can we reduce variability in costing methods? Journal of Technology Assessment in Health Care, 19 (2), pp. 407-420.

Baca-Urbina, G. (2013). Evaluación de proyectos. Mc Graw Hill.

Capra, F. (1996). La trama de la vida. Una nueva perspectiva de los sistemas vivos. España: Anagrama. http://medicinaycomplejidad.org/ pdf/reciente/

Capra_Fritjof_La_trama_de_la_vida.pdf

Chávez-Gómez, P., Ramirez-Sigala, M. y San JuanGamiño, F.S. (2019). Natación sustentable para todos: Transformando las albercas públicas en piscinas ecológicas con depuración hidropónica en Zapopan, Jalisco. Gobierno de Zapopan: Incide, tu voz mueve la ciudad.

Consejo Municipal del Deporte, COMUDE (2020). Mapa de unidades deportivas. https:// www.portal.comudeguadalajara.gob. $\mathrm{mx} /$ ubicacion_poligonos.php

Comisión Nacional del Agua, CONAGUA (2018). Tarifas de agua potable y saneamiento para uso doméstico tipo residencial. http:// sina.conagua.gob. $\mathrm{mx} / \mathrm{sina} / \mathrm{tema} . \mathrm{php}$ ?

tema=tarifas

Daly, H. (1977). Steady state economics. EE.UU: Island Press.

Diario Oficial de la Federación (DOF) (2012). NOR-

MA Oficial Mexicana NOM-245-SSA1-2010,

Requisitos sanitarios y calidad del agua que deben cumplir las albercas. https:// www.dof.gob.mx/nota_detalle.php? codigo $=5256066 \&$ fecha $=25 / 06 / 2012$

El Universal (2019, enero 29). Suspende FMN a Jalisco por nadadores intoxicados. El Universal. https://www.eluniversal.com.mx/universaldeportes/mas-deportes/suspende-federacionmexicana-de-natacion-jalisco-por-nadadores

Gallardo-Martínez, G., Arias-Cruz, A., GonzálezDíaz, S. N. y Galindo-Rodríguez, G. (2007). Costos derivados de la atención médica del asma en un grupo de niños del Noroeste de México. Revista Alergia México 54(3), 82-85.

Geraldes, A. M., Schwarzer, C. y Schwarzer, U. (2014). Piscinas Biológicas e Serviços Ecossistémicos: Que Relação? CAPTAR, 5(2), pp. 27-36. https://www.researchgate.net/ publication/322077903_Piscinas_Biologicas_e_Servi cos_Ecossistemicos_Que_Relacao

Morales-Ortizn, E. (2010). Propuesta educativa «El agua como medio de enseñanza: importancia de la evaluación» RETOS. Nuevas Tendencias en Educación Física, Deporte y Recreación, 17, pp. 72-75. https://www.redalyc.org/ pdf/3457/345732283015.pdf

Helenius, I. y Haahtela, T. (2000). Allergy and asthma in elite summer sport athletes. J Allergy Clin Immunol. 106(3), pp. 444-52. https:// doi.org/10.1067/mai.2000.107749

Henderson, N. y Bateman, I. (1995). Empirical and public choice evidence for hyperbolic social discount rates and the implications for intergenerational discounting. Environmental \& Resource Economics, 5(4), pp. 413-423.

Kiin (2020). Biopiscinas. https://huulkiin.com.mx/biopiscinas/

Instituto Nacional de Estadística y Geografía, INEGI (2010). Marco Geoestadístico. https:// www.inegi.org.mx/temas/mg/\#Descargas

Jevons, S. (1866). The Coal Question. An inquiry 
Las ecotecnias como factor de sustentabilidad. El caso de las biopiscinas municipales en la ciudad de Guadalajara Salvador Peniche Camps, Pedro Chávez Gómez

Hatso Hnini Revista de Investigación de Paisajes y Espacio Construido

Vol.1 Núm.1 Año 2021

concerning the porgress of the nation and the probable exhaustion of the coal mines. London: Mcmillan. https://oll-resources.s3.useast-2.amazonaws.com/oll3/store/ titles/317/0546_Bk.pdf

Leff, E. (2004). Racionalidad ambiental. La reapropiación social de la naturaleza. México: S XXI. https://books.google.com.mx/books/ about/Racionalidad_ambiental.html?

id=igF_kdwY3MMC_\&printsec=frontcover\&sou rce $=\mathrm{kp}$ _read_button\&redir_esc $=\mathrm{y} \# \mathrm{v}=\mathrm{onepag}$ $\mathrm{e} \& \mathrm{q} \& \mathrm{f}=\mathrm{false}$

Llana, S., Zarzoso, M. y Pérez, P. (2009). Riesgos para la salud de la natación en piscinas cloradas (II). Archivos de Medicina del Deporte, 26(131), pp. 218-227. https:// archivosdemedicinadeldeporte.com/articulos/ upload/revision_riesgos_218_131.pdf

Mapfre (2007). Estudio de Situación del Sector de Mantenimiento y Conservación de Instalaciones Acuáticas. https://app.mapfre.com/ccm/ content/documentos/empresas/fichero/

Prevencion_estudio_instalaciones_instalaciones_ac uaticas.pdf

Marcuse, H. (1954). El hombre unidimensional. Ensayo sobre la ideología de la sociedad industrial avanzada. España: Planeta. https:// monoskop.org/images/9/92/

Marcu-

se_Herbert_El_hombre_unidimensional.pdf

Morales-Ortizn, E. (2010). Propuesta educativa «El agua como medio de enseñanza: importancia de la evaluación» RETOS. Nuevas Tendencias en Educación Física, Deporte y Recreación, 17, pp. 72-75. https://www.redalyc.org/ pdf/3457/345732283015.pdf

Navarro-Valdivielso, F. (1990). Hacia el dominio de la natación. Editorial Gymnos.

Noval-Gómez, L. (2017). El cloro, producción e industria. [Tesis de maestría, Universidad de Educación a Distancia, Facultad de Ciencias, Departamento de Química Inorgánica y Química Técnica]. Archivo digital. http://espacio.uned.es/fez/eserv/bibliuned:masterCiencias-CyTQ-Lnoval/

Noval_Gomez_Lucia_TFM.pdf

ONU (2021). Objetivos del desarrollo sostenible. https://www.un.org/sustainabledevelopment/ es/economic-growth/

Peña, P. (2018, diciembre 17). Suspenden Jornada Nacional de Natación en Jalisco. El Diario. https://www.ntrguadalajara.com/post.php? id_nota $=115196$

Pérez-Quintero, F., Guardia-Pueblas, Y. y Rodríguez -Pérez, S. (2017). La fitoremediación para el tratamiento de aguas de piscinas. Ingeniería hidráulica y Ambiental, 38(3), pp. 101-113. http://scielo.sld.cu/scielo.php? script=sci_abstract\&pid=S168003382017000300009

Presidente y Ministra de Salud de la República de Costa Rica (2009). Decreto $N^{\circ} 35309-S$ del 30/03/2009: Reglamento Sobre Manejo de Piscinas. http://www.labmicrotec.com/wpcontent/uploads/2016/02/ReglamentoPiscinas-1.pdf

Riechmann, J. (2008). Biomímesis. Ensayos sobre la imitación de la naturaleza, eco socialismo y autocontención. España: Libros de la catarata.

Sánchez-Rodríguez, J.J. (2011). Estudio de la implantación de piscinas ecológicas en las piscinas municipales de Cataluña [Tesis de pregrado, Departament de Projectes d'Enginyeria. Universitat Politécnica de Catalunya]. Archivo digital. https://upcommons.upc.edu/ bitstream/handle/2099.1/11554/ MEMORIA.pdf

The Economics of Ecosystems \& Biodiversity (TEEB) (2020). Natural Capital Accounting. http://teebweb.org/our-work/nca/ 